\title{
Psicossomática do prazer feminino
}

Amparo Caridade*

De que goza e de que sofre o feminino em sua particularidade, em sua cultura, em seu tempo? Essa é uma questão que levanto aqui buscando compreensão para as dimensões da dor e do gozo no universo feminino. Dor que é sentida na psiquê, que vai ser expressa no corpo, que talvez se faça sintoma, dor que é silenciada pelo cultural cada vez mais minimizador do sentir. Contraponho a isso porém a imensa capacidade do feminino para o gozo, fato que é também silenciado. Porque se fala hoje, do dever da mulher de gozar, mas não de sua potencialidade de gozo. A partir desse silêncio interrogo sobre as dores que persistem para o feminino nesse final de século.

Para isso apoio-me no desafio posto pela Psicossomática, de ver o homem como um ser indivisível, uma integração bio-psíquica, uma interação mente/corpo/cultura/meio ambiente. Os paradigmas mais recentes evidenciam a importância desse entrelaçamento e indicam que a natureza deve ser entendida como uma rede dinâmica de eventos interrelacionados,

* Psicóloga. 
onde nenhuma parte é mais relevante que qualquer outra. Essas idéias sugerem uma interconceptualidade que é extremamente necessária ao entendimento do que se passa na pessoa. $\mathrm{O}$ todo tem uma dimensão integradora, porque é na organização das partes que se dá a harmonia que está na ordem. Uma ordem que procede do entrelaçamento das partes. Isso implica que uma parte tem a ver com o todo e que esta só pode ser compreendida nessa relação de totalidade.

O sentir feminino é uma experiência profunda, é uma experiência integrada. O feminino dói na internalidade, no silêncio de seu mais íntimo, numa ordenação dos aspectos que compõem a experiência dolorosa. A sensibilidade exaltada no feminino, possibilita que a pessoa viva dores intensas e prazeres extasiantes. O feminino então dói e goza com muita intensidade, ao contrário do que é veiculado. Não me refiro aqui apenas ao feminino que está na mulher. Não. O feminino é um sistema de pensamento, é uma forma de ser, não é um património da mulher. Um homem a uma mulher habitam o mais dentro da pessoa. O sentir feminino procede dessa sensibilidade que remete o sujeito ao sentir dentro.

De que dói a goza o feminino que está na mulher? Mulher dói e goza das palavras ditas, não ditas, mal ditas, bem ditas. Dói e goza das linguagens que lhe circundam, dos gestos feitos e da falta deles; sofre e goza das diferenças em sua nuances de partilha e desigualdade. Mulher dói de não ser reconhecida como sujeito, como cidadã. A discriminação dói no corpo e no espírito. Dói do não sentir-se amada, do não poder amar, do não poder fazer amor. Dói de não ser valorizada em seu crescimento, a do medo que causa aos homens esse seu crescimento. Mulher dói de ser coisa, pedaço, bunda, objeto, mercadoria. Quem não viu a dor e o desespero daquela garota asiática ao ser negociada sua venda com nosso repórter brasileiro? Quem não ouviu seus gritos de desepero? Quem não viu seu sorriso quando o equívoco se desfez? São algumas das dores culturais que se abatem sobre a mulher. Mas ela não dói apenas. Diria também que ela goza. Goza de si mesma como sujeito, como amante, ela goza de estar em parceria, de apaixonar-se, de maravilhar-se com o outro, de entregar-se, de ser mãe, mulher, profissional e intelectual. Ela goza de tocar e ser tocada, com doçura e firmeza. Mulher goza de ser alcançada em seu jeito próprio de viver e amar, de poder perder tempo olhando, apenas olhando, de consultar o espelho e colorir os lábios, de seduzir, de fazer coisas simples que podem encantar o cotidiano, como gosta de entender as transformações do mundo, do ser humano, do fim de século e do próximo milênio que se aproximam. Basta olhar o número de mulheres que invade as Universidades e os diversos Congressos e reuniões científicas. 
Plasmando as condutas, a cultura construiu artifícios e jogos de linguagem e difundiu uma subestima em relação ao feminino. Não deve ser por acaso que na lingua, dor seja uma palavra feminina e gozo, prazer, sejam palavras masculinas. Que loucura seja feminina e que juízo seja masculino. Que, mesmo que sejamos 1000 mulheres reunidas e um só homem, a concordância gramatical tenha de ser no masculino. Todo um paradigma de superioridade que também criou históricas expressões que insinuam a não importância do prazer feminino. "Mulher não goza, não precisa de gozo, mulher recatada não busca o gozo. Gozo é coisa de puta"... Por que tanta necessidade de rechaço, negação e de silêncio acerca do prazer feminino se a mulher é, por excelência, um ser sensível e amoroso? Por que terá ela se mantido por tanto tempo nesse lugar?

A cultura também é cruel contra o feminino que está no homem. O modelo de homem que é imposto expurga de sua experiência qualquer sentimento dessa ordem. Por isso ele rechaça e menospreza a mulher. Quanto mais periférica, tola, inculta é uma cultura, mais ela exige que seus homens se precavenham contra sua porção feminina, que se castrem de sua doçura, o que é lamentável, pois nada mais bonito que o animal terno que emerge do homem bem resolvido com sua cultura e com seu feminino.

A linguagem da cultura também é marcante no que se refere aos destinos do prazer feminino. Após quase 2000 anos de silêncio e de negação disso, o discurso da modernidade anuncia que as mulheres devem gozar - e gozar um gozo múltiplo, sob pena de que, outros discursos lhe chamem de frígidas, desprazerosas e anorgásmicas. Dimensões tão íntimas, tão internas do indivíduo, não deveriam ser protegidas da manipulação do social, não são da competência interns do sujeito? Mas a apropriação do sexo pela ciência nos trouxe no mínimo o benefício de enquadrá-lo, classificá-lo, patologizá-lo. A palavra dos pais, da escola, da Igreja, da medicina, do social, da globalização, se constituem como a lei e conferem um tom valorativo e emocional, que atravessa o viver da pessoa.

Gozo e dor não são dados da aparência mas da internalidade, ambos procedem da fundura do sujeito. A cultura aplaude apenas o prazer periférico, que não deixa marcas. Gozar não é uma experiência periférica. Doer tampouco. Na Sociedade do Espetáculo (1), palco por excelência do parecer, falta aconchego para a interioridade e o sujeito fica cada vez mais distanciado, tanto de seu transtorno como de sua verdadeira alegria, de seu êxtase, fato que o manterá na periferia de si mesmo. No entanto é nesse lugar mais interno que se dão as experiências de maior aprofundamento do 
ser. O êxtase da partilha amorosa ou a ferida narcísica de não sentir-se amada, desejada, é algo vivido muito dentro, não na aparência.

Haverá diferenças entre a sensibilidade masculina e feminina? Maria Rita Kehl em A Mínima Diferença (2), mostra a força que tem a cultura e suas linguagens, nessa questão das diferenças: “... é a cultura que nos designa destinos diferenciados como homens ou mulheres", daí porque, para os lacanianos, "a linguagem é o destino". A linguagem torna-se o grande veículo dessa diferenciação. É o que é dito que nos refere como diferentes. A linguagem é performativa do sujeito, diz Jurandir Freire. A linguagem é performativa também do feminino.

Nasio (3) considera a dor psíquica como "uma lesão do laço íntimo com o outro". Esse tipo de dor pode ser vivido tanto pelo homem como pela mulher. Uma certa diferença perpassa talvez a questão da entrega ao sentir, dimensão que é muito estimulada na mulher a banida na experiência masculina. Essa diferença passaria por isso que diz Nasio: "Na fantasia da mulher, o objeto mais precioso, o falo, é o amor que vem do amado, e não o próprio amado. Assim a angústia especificamente feminina é o medo de perder o amor e ver-se abandonada" (idem). Aí está a diferença: para a mulher, o falo não é o pênis, mas o amor, é o sentir-se desejada. Aí ancora-se seu grande gozo.

Cuidar do sofrimento humano nos possibilita a compreensão da dor como o ponto de ligação entre o corpo e a psiquê. A dor física é intercambiada com o psiquismo, é representada, simbolizada, significada, de tal modo que a pessoa pode confundir um conteúdo afetivo doloroso com a própria sensação de dor corporal, tornando difícil precisar quando se fala de uma dor física ou emocional. Também quando ocorre uma dor física esta vem tão superinvestida da representação do órgão lesado, que passa a ocupar grande parte do espaço vital. Isso resulta inclusive num desinvestimento do indivíduo pelos demais aspectos da vida. O eu é uma instância corporal e psíquica. A dor então pode ser psicogência, pode surgir sem nenhuma causa orgânica que a justifique.Algumas dores contemporâneas do feminino perpassam a escuta clínica, como a dor da mulher que cresceu e debate-se com o medo de ficar só, pela dificuldade de encontrar um parceiro que aceite e partilhe de seu crescimento, sem sentir-se ameaçado por isso, ou a dor da disparidade das possibilidades de parceria entre homens e mulheres, sobretudo quando se trata da mulher idosa. Há quem pense que essa é uma questão resolvida nos dias atuais. Numa sociedade como a nossa, em que prevalece a aparência, a questão mantém-se. De modo que, um homem pode encontrar parcerias cada vez mais jovens enquanto que uma mulher madura pode confrontar-se com o ter de ficar só. Há pouco tempo Woody Allen, sessentão sedutor, conquistava uma mulher 35 anos 
mais jovem, e o fato foi visto com graciosa normalidade. Numa mulher sessentona, o fato cheiraria a escândalo. Se, como diz R. Alves, "O amor ignora os abismos do tempo", interrogo-me sobre o que está acontecendo ao amor neste nosso tempo? Na prática do relacional fundada no parecer, o tempo inscrito no corpo feminino pesa e discrimina sim. O que é atraente aos espectadores da sociedade do espetáculo é o que ela estampa, não o que ela é, o que ela alicerçou de sabedoria amorosa.

O mais cômodo para a cultura ante a questão do tempo inscrito no corpo da mulher, é difundir o equívoco de que, nessa idade, a baixa de estrógenos promove um desinteresse feminino pela função sexual. Não é isso porém o que dizem as mulheres em resposta a uma pesquisa realizada pela UERJ, no Rio de Janeiro (Revista Manchete, janeiro 98). O que elas dizem é que não mantêm vida sexual ativa por falta de parceiros. A questão dessas mulheres não é desinteresse, mas falta de oportunidade para interessar-se. Cada tempo, cada cultura, impede a possibilita o acontecer feminino. As mulheres desse fim de século iniciaram uma desconstrução de modelos opressores do nosso gozo. É preciso agora não nos perdermos nas malhas das próprias repressões. Uma multiplicidade de lugares se revelam hoje ao feminino. Faz-se necessário que nos curemos dos lugares impostos pela cultura, e que transitemos mais levemente por estes lugares, brincando até com as polaridades, dialetizando as diferenças. Nossa saúde emocional precisa descolar da história nada lisonjeira à mulher, para decolar sumo a outras condições de viver. Imagino que nossa cura depende de flexibilidade, da mobilidade psíquica de cada uma para transitar na agonia e no êxtase dos "tristes e alegres sofrimentos da gente", como dizia G. Roza.

\section{REFERÊNCIAS BIBLIOGRÁFICAS}

1. DEBORD, G. A sociedade do espetáculo. Contraponto. Rio de Janeiro, 1997.

2. KHEL, M. R. A mínima diferença. Imago. Rio Janeiro, 1996.

3. NASIO, J. D. O livro da dor e do amor. Jorge Zahar. Rio de Janeiro, 1997. 